UDC $338.984+622.691$

LBC 65.730+65.237.03

\title{
SHORT-TERM FORECASTING OF THE PARAMETERS OF NATURAL GAS CONSUMPTION AS AN ELEMENT OF PRICE-DEPENDENT MANAGEMENT OF ENERGY COSTS IN INDUSTRIAL ENTERPRISES
}

\author{
Anatoliy P. Dzyuba \\ Gazenergosbyt LLC, Chelyabinsk, Russian Federation
}

Irina A. Solovyeva

South Ural State University (National Research University), Chelyabinsk, Russian Federation

\begin{abstract}
Natural gas is one of the most used energy resources in the world. The authors propose the method for reducing the costs of natural gas procurement, which consists in the use of a tool for managing the demand for natural gas consumption by industrial enterprises.

The article contains the authors' description of the mechanism for reducing the costs of natural gas procurement at the level of the UGSS of Russia through the application of the demand management mechanism. Based on the characteristics of the technological and market environment, the authors develop a model for price-dependent management of natural gas consumption in an industrial enterprise, with the definition of key model blocks and the sequence of functions performed.

The key element of the developed model of price-dependent management is the unit for fulfilling the forecast of natural gas consumption. The article analyzes the characteristics of the graphs of natural gas consumption by various types of industrial enterprises at different periods. The authors reveal a list of factors affecting the characteristics of natural gas consumption schedules by industrial enterprises. The influence of the identified types of factors on gas consumption in various industries has been assessed. Based on the revealed features, the authors developed a model for forecasting short-term demand parameters for gas consumption by industrial $\infty$ enterprises, based on using a combined forecasting method that combines the use of statistical methods and the $\stackrel{\sim}{\circ}$ method of expert assessments.

The developed combined model for forecasting the parameters of natural gas consumption makes it possible to significantly improve the accuracy of forecasts by breaking up the consumption schedule by the types of gas use, taking into account the specifics and the level of influence of factors within each direction of consumption, and using the most suitable methods for each group of prediction methods. The practical importance of the developed model lies in the possibility of its use for forecasting the parameters of natural gas consumption by any types of industrial enterprises in the context of price-dependent energy management in order to minimize them.

Key words: forecasting, natural gas consumption, costs management, demand management, energy costs, energy efficiency, modeling, industry.
\end{abstract}




\title{
КРАТКОСРОЧНОЕ ПРОГНОЗИРОВАНИЕ ПАРАМЕТРОВ ПОТРЕБЛЕНИЯ ПРИРОДНОГО ГАЗА КАК ЭЛЕМЕНТ ЦЕНОЗАВИСИМОГО УПРАВЛЕНИЯ ЭНЕРГОЗАТРАТАМИ НА ПРОМЫШЛЕННЫХ ПРЕДПРИЯТИЯХ
}

\author{
Анатолий Петрович Дзюба \\ ООО «Газэнергосбыт», г. Челябинск, Российская Федерация
}

Ирина Александровна Соловьева

Южно-Уральский государственный университет (национальный исследовательский университет), г. Челябинск, Российская Федерация

Аннотация. Одним из самых используемых энергетических ресурсов, потребляемым во всем мире, является природный газ. В качестве одного из методов снижения затрат на закупку природного газа авторами предлагается использование инструмента управления спросом на потребление газа промышленных предприятий.

В статье предлагается авторское описание механизма снижения затрат на закупку природного газа на уровне ЕСГ России посредством применения механизма управления спросом. На основе особенностей параметров технологической и рыночной среды авторами разработана концепция модели ценозависимого управления потреблением природного газа на промышленном предприятии, с определением ключевых блоков модели и последовательности выполняемых функций.

Ключевым элементом разработанной модели ценозависимого управления является блок выполнения прогноза потребления природного газа. В статье проводится анализ характеристик графиков потребления природного газа различными типами промышленных предприятий на разных периодах. Авторами выявлен перечень факторов, действующих на характеристики графиков потребления природного газа промышленными предприятиями. Проведена оценка влияния выявленных типов факторов на потребление газа в различных отраслях промышленности. На основании выявленных особенностей авторами разработана концепция модели прогнозирования краткосрочных параметров спроса на потребления газа промышленными предприятиями, основанная на использовании комбинированного метода прогнозирования, сочетающая в себе использование статистических методов и метода экспертных оценок.

Разработанная концепция комбинированной модели прогнозирования параметров потребления природного газа позволяет существенно повысить точность прогнозов за счет разбивки графика потребления по видам использования газа, учета специфики и уровня влияния факторов в рамках каждого направления потребления и использования наиболее подходящих для каждой группы факторов методов прогнозирования. Практическая значимость разработанной модели заключается в возможности использования разработанной модели прогнозирования параметров потребления природного газа любыми типами промышленных предприятий в рамках ценозависимого управления энергозатратами с целью их минимизации.

Ключевые слова: прогнозирование, потребление природного газа, управление затратами, управление спросом, энергозатраты, энергоэффективность, моделирование, промышленность.

Одним из ключевых направлений модернизации и инновационного технологического развития развитых и развивающихся стран мира является реализация механизмов энергосбережения и повышения энергетической эффективности. Программы энергосбережения и повышения энергетической эффективности имеют общенациональные масштабы, и направлены на снижение затрат на энерго- потребление во всех уровнях хозяйственной деятельности и по всем видам энергетических ресурсов.

Одним из самых используемых энергетических ресурсов, потребляемым во всем мире, является природный газ, по распространенности потребления уступающий лишь электрической энергии. Газ характеризуется относительно невысокой стоимостью, просто- 
той трубопроводной транспортировки и распределения, легкостью преобразования в другие виды энергии и экологичностью. Без использования природного газа невозможно эффективное развитие важнейших отраслей промышленности, таких как цветная и черная металлургия, металлообрабатывающая, цементная, химическая и нефтехимическая, нефтеперерабатывающая промышленности, машиностроение и других. Также большое количество природного газа используется в секторе ЖКХ [7].

Значительное внимание к проблеме энергосбережения в последнее десятилетие привело к существенному развитию технологий и методов повышения энергетической эффективности. Большинство внедряемых технологий направлено на снижение удельного потребления энергетических ресурсов. Однако в последнее время все большее распространение получает инновационная технология управления спросом на потребление энергетических ресурсов [12-14].

В современной мировой практике технология управления спросом применяется исключительно в направлении потребления электрической энергии $[11 ; 15 ; 16]$. С нашей же точки зрения представляется возможным адаптировать существующие подходы к управлению спросом на потребление электрической энергии к процессам потребления природного газа.

Под управлением спросом на потребление природного газа мы предлагаем понимать инициативную форму экономического взаимодействия субъектов газового комплекса с конечными потребителями природного газа, обеспечивающую взаимовыгодное экономически эффективное регулирование объемов и режимов потребления газа. Управление спросом на потребление природного газа должно способствовать выравниванию графиков потребления газа в масштабах Единой системы газоснабжения и, как следствие, снижению затрат на газоснабжение на всех ее уровнях $[4 ; 5]$. Одним из направлений управления спросом является метод ценозависимого управления затратами на потребление природного газа, который заключается в управлении собственными графиками потребления газа потребителями с целью их выравнивания и исключения закупок газа по тарифам, установленным для объемов потребления газа, выбираемых сверх существующих договорных лимитов. В качестве субъекта управления выступает организационная и технологическая инфраструктура газового комплекса. В качестве объекта управления выступает процесс потребления газа конечными потребителями.

В действующих экономических условиях поставок газа в России цена на поставляемый газ не является дифференцированной по времени суток. При этом ценовая дифференциация поставляемого газа применяется для объемов, выбранных сверх суточных лимитов, выставляемых системой газоснабжения для каждого потребителя газа. Разработанная авторами модель ценозависимого управления потреблением природного газа на промышленных предприятиях представлена на рисунке 1.

Одним из ключевых элементов модели ценозависимого управления потреблением природного газа является блок прогноза его потребления. Сопоставляя прогнозные параметры потребления газа в будущих периодах и ценовые параметры энергорынка, разрабатываются управляющие воздействия на графики потребления природного газа с целью минимизации затрат на его оплату.

В связи с этим высокую научную и практическую значимость имеет задача разработки такой модели прогнозирования краткосрочных параметров потребления природного газа, которая будет отличаться относительной простотой, точностью и адаптивностью применения на различных типах промышленных предприятий.

В настоящий момент в отечественной и зарубежной практике существует достаточно большое количество исследований, посвященных разработке моделей прогнозирования потребления природного газа. Часть работ посвящена исследованию вопроса долгосрочного прогнозирования параметров спроса на природный газ различными экономическими субъектами [3; 6]; есть исследования, посвященные прогнозированию параметров спроса на потребление газа в разрезе отдельных стран и регионов $[9 ; 10]$; часть работ акцентирует внимание на разработке 
А.П. Дзюба, И.А. Соловьева. Прогнозирование параметров потребления природного газа

Bходные параметпы

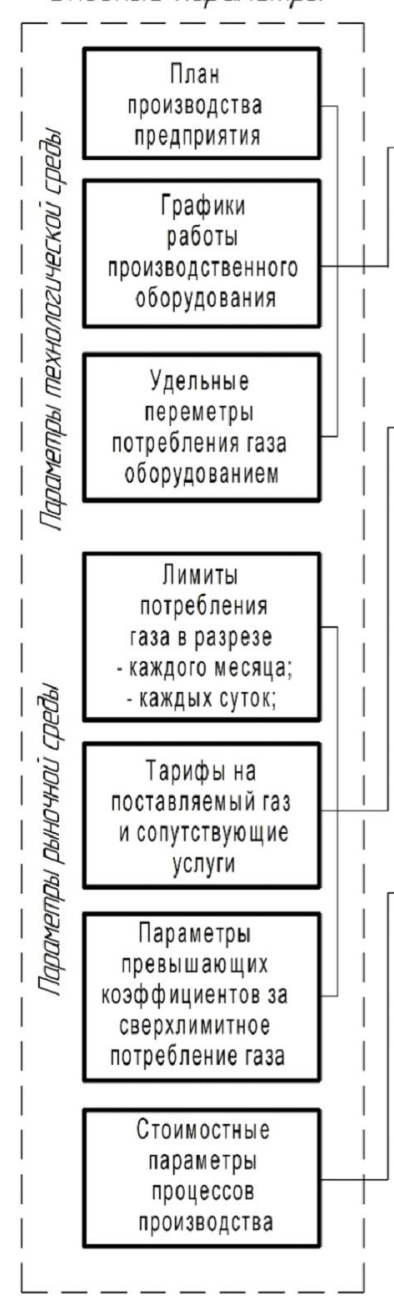

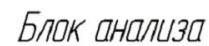

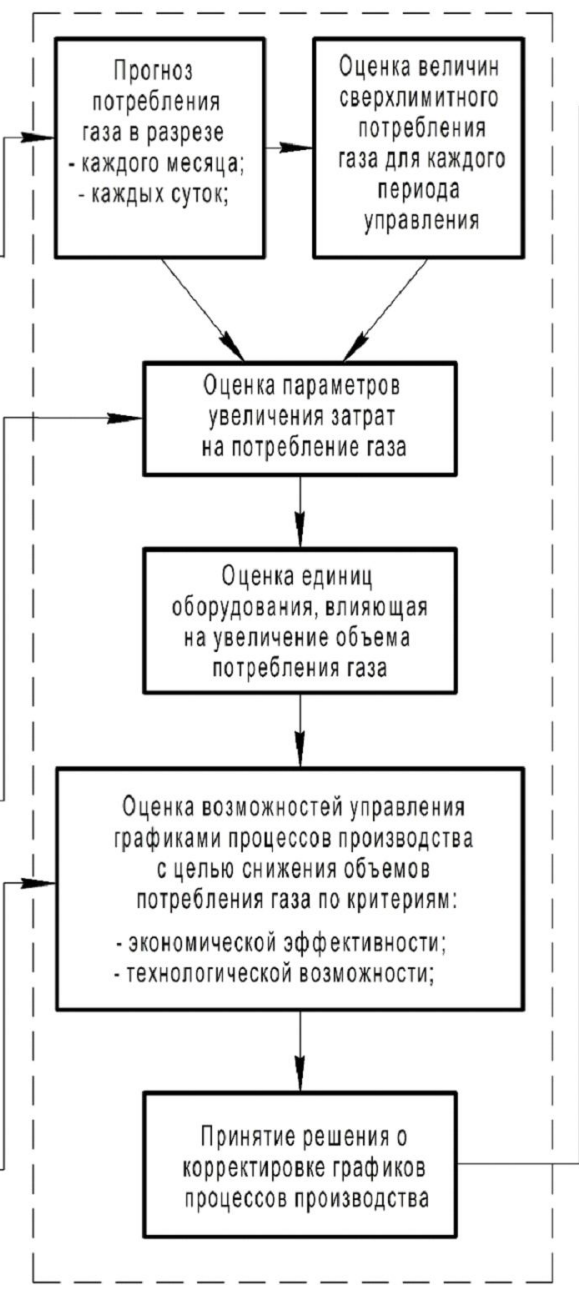

Бпок чправпения

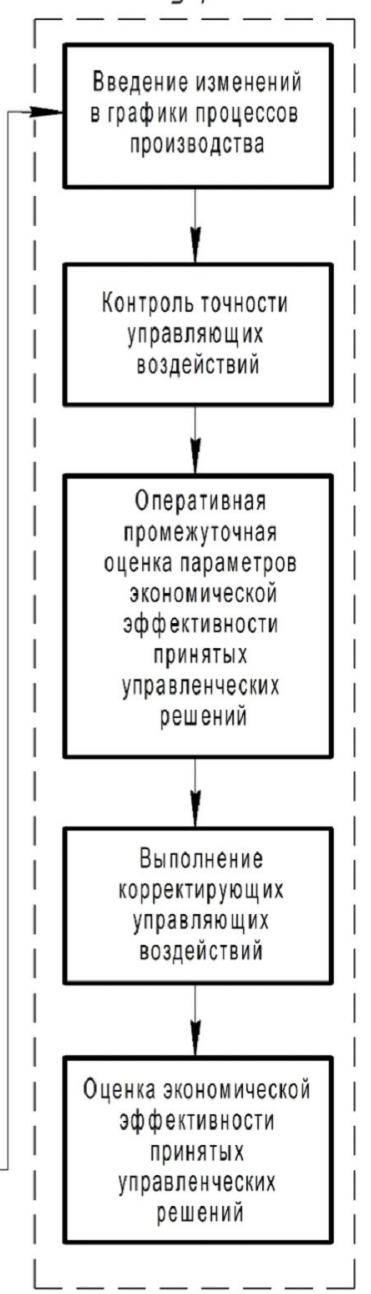

Рис. 1. Модель ценозависимого управления потреблением природного газа на промышленном предприятии

Примечание. Составлено авторами.

моделей прогнозирования спроса на газ в разрезе отдельных отраслевых групп $[1 ; 2$; 8]. При этом практически отсутствуют исследования, посвященные разработке моделей прогнозирования краткосрочных параметров спроса на потребление природного газа, характеризующихся универсальностью и способностью адаптироваться под индивидуальные характеристики различных типов промышленных предприятий.

Таким образом, целью настоящего исследования является разработка концепции универсальной модели краткосрочного прогнозирования параметров потребления природного газа различными типами промышленных предприятий.

Для достижения поставленной цели необходимо решить несколько задач, таких как:
- анализ графиков краткосрочного потребления природного газа промышленными предприятиями и выявление характеристик волатильности спроса на различных временных периодах;

- выявление факторов, влияющих на параметры спроса на потребление природного газа и их классификация;

- выбор методов прогнозирования параметров краткосрочного потребления природного газа;

- разработка концепции модели прогнозирования краткосрочных параметров потребления природного газа для различных типов промышленных предприятий.

Графики потребления природного газа могут быть: годовыми, месячными, недельными, суточными, часовыми и т. д. В модели це- 


\section{УПРАВЛЕНИЕ ЭКОНОМИЧЕСКИМ РАЗВИТИЕМ}

нозависимого управления затратами на потребление природного газа используются месячные и суточные графики потребления.

На рисунке 2 приведен пример месячного графика потребления природного газа за календарный год для различных типов промышленных предприятий. Как видно из диаграммы, помесячный спрос на потребления газа для всех типов промышленных предприятий характеризуется волатильностью, обусловленной, прежде всего, сезонностью и индивидуальными характеристиками производственных процессов. Для промышленных предприятий, использующих природный газ на отопительные нужды, характерно высокое потребление газа в период отопительного сезона. Для предприятий, использующих природный газ на производственные нужды, график потребления газа является более равномерным, с незначительным спадом потребления в период потепления. Для предприятий по производству цемента волатильность потребления газа связана с сезонностью производства и отгрузок продукции.
Волатильность потребления природного газа предприятиями химической промышленности напрямую обусловлена графиками производственной программы.

На рисунке 3 представлен пример посуточного графика потребления газа различными типами промышленных предприятий за неделю. Очевидно, что в разрезе недельного периода для всех типов промышленных предприятий волатильность спроса значительно ниже, по сравнению с месячным периодом. Для промышленных предприятий, использующих природный газ на отопительные нужды, основная нагрузка потребления газа приходится на рабочие дни с незначительным снижением к выходным. У предприятий, использующих природный газ на производственные нужды, спад потребления газа в выходные дни более значительный. Для коммунальных котельных нагрузка потребления газа зависит от температуры окружающей среды, а для электростанций график потребления газа полностью коррелирует с графиком потребления электрической энергии.

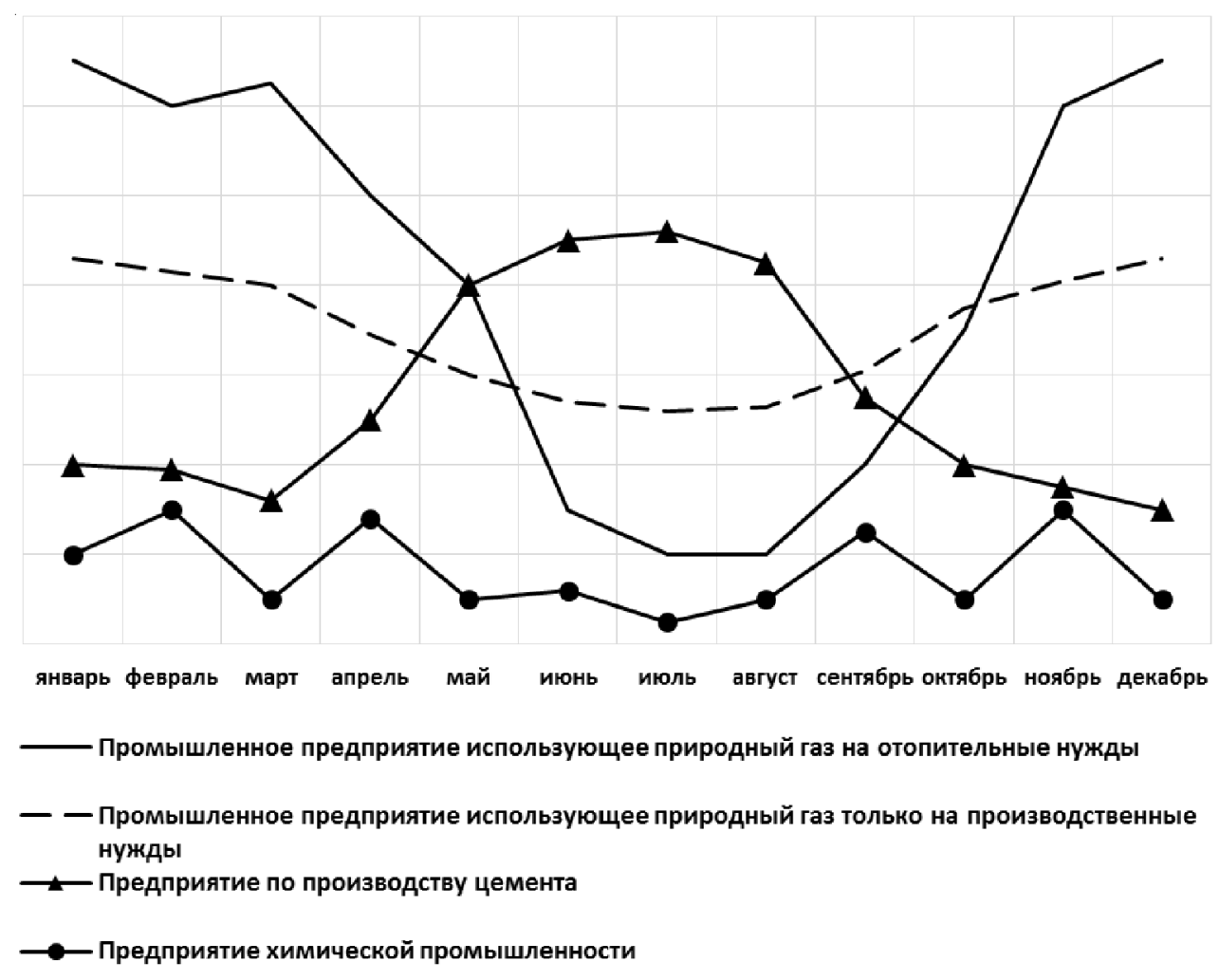

Рис. 2. Помесячные графики потребления газа за календарный год различными типами промышленных предприятий

Примечание. Составлено авторами на основе анализа статистики потребления природного газа АО «Пермский завод “Машиностроитель”», МЗ «Камасталь», ООО «Староцементный завод», ПАО «Уралкалий». 


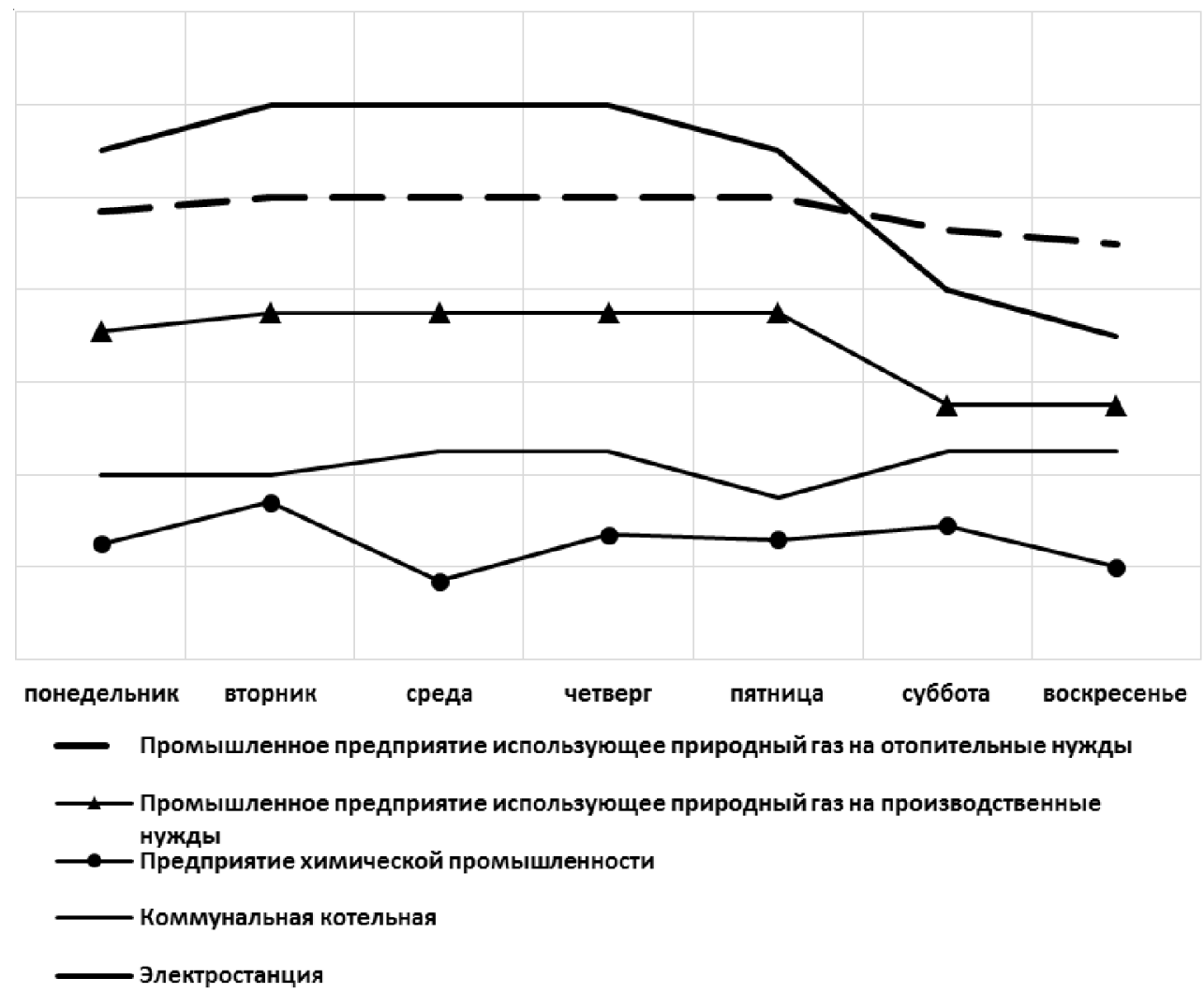

Рис. 3. Посуточный график потребления газа различными типами промышленных предприятий в разрезе недели

Примечание. Составлено авторами на основе анализа статистики потребления природного газа $\mathrm{AO}$ «Пермский завод “Машиностроитель”», МЗ «Камасталь», ООО «Староцементный завод», ПАО «Уралкалий».

На рисунке 4 представлен пример графиков почасового потребления газа промышленными предприятиями, использующими природный газ на производственные и отопительные нужды.

В случае потребления газа на производственные нужды почасовой график потребления повторяет график загрузки производственных процессов, а при потреблении газа на отопительные нужды график спроса обратно пропорционален температуре воздуха.

Подводя итог оценке характеристик графиков потребления природного газа промышленных предприятий, можно констатировать их существенную волатильность и высокую зависимость от климатических условий, отраслевой принадлежности предприятия и структуры потребления газа. На рисунке 5 обобщены особенности графиков потребления газа в разрезе двух основных направлений его использования: на производственные нужды и на отопительные цели.

Предложенная классификация направлений потребления природного газа обусловлена:
- характеристиками волатильности графиков потребления газа;

- различием факторов, действующих на потребление газа в данных направлениях;

- различием методов управления графиками потребления газа для данных направлений;

- массовостью использования выявленных направлений потребления газа на промышленных предприятиях.

К направлению технологии производства относится потребление газа на обеспечение технологических процессов производства продукции, нагрева, обжига, сушки используемого сырья и материалов, а также добычи из природного газа необходимых веществ.

К направлению отопительных нужд и горячего водоснабжения (ГВС) относится потребление газа на обеспечение отопительных нужд в период отопительного сезона, требуемых для внутреннего потребления предприятием либо отпуском тепловой энергии и горячего водоснабжения потребителям. 


\section{УПРАВЛЕНИЕ ЭКОНОМИЧЕСКИМ РАЗВИТИЕМ}

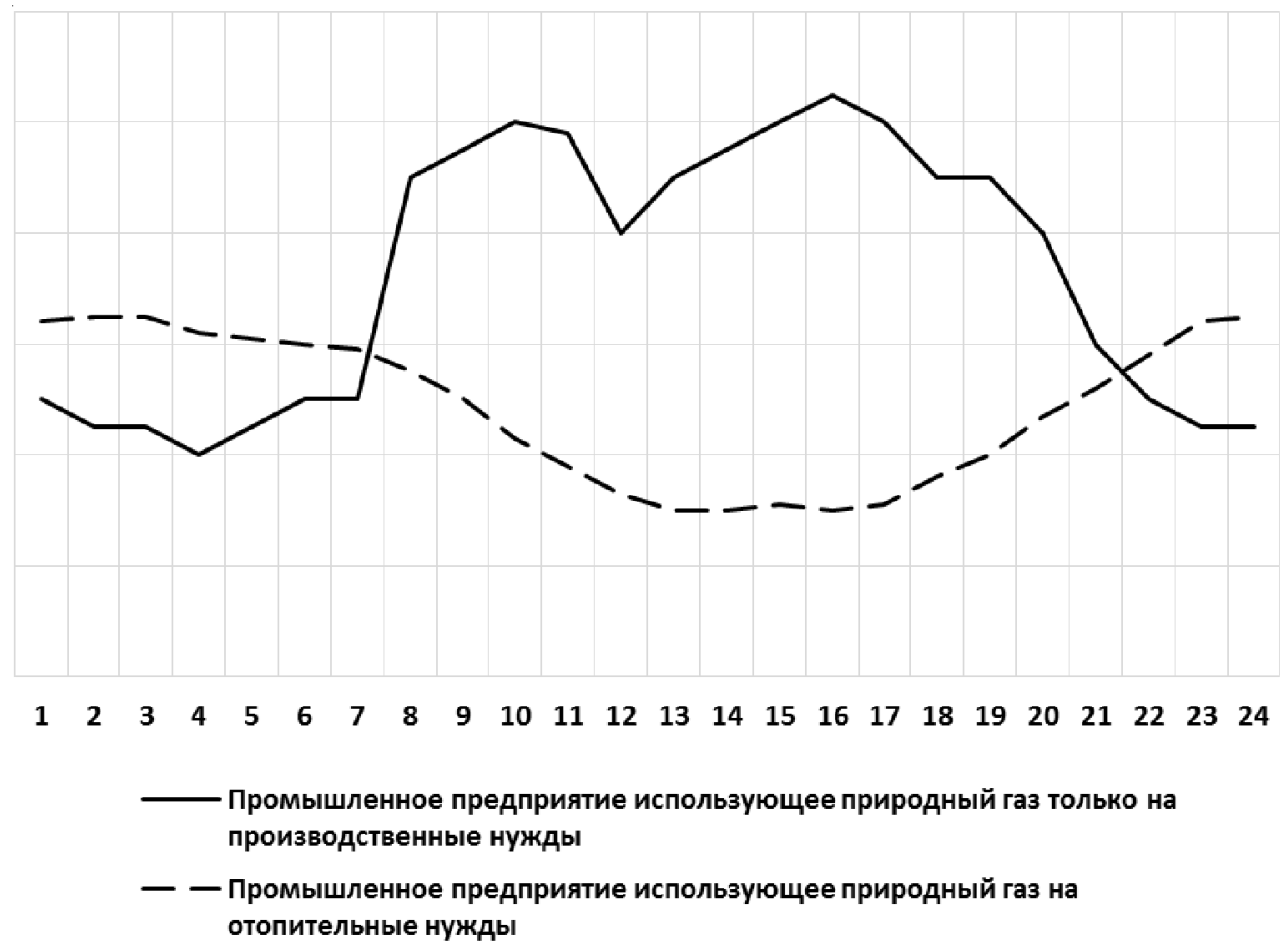

Рис. 4. Пример почасовых графиков потребления газа различными типами промышленных предприятий в разрезе суток

Примечание. Составлено авторами на основе анализа статистики потребления природного газа промышленными предприятиями.

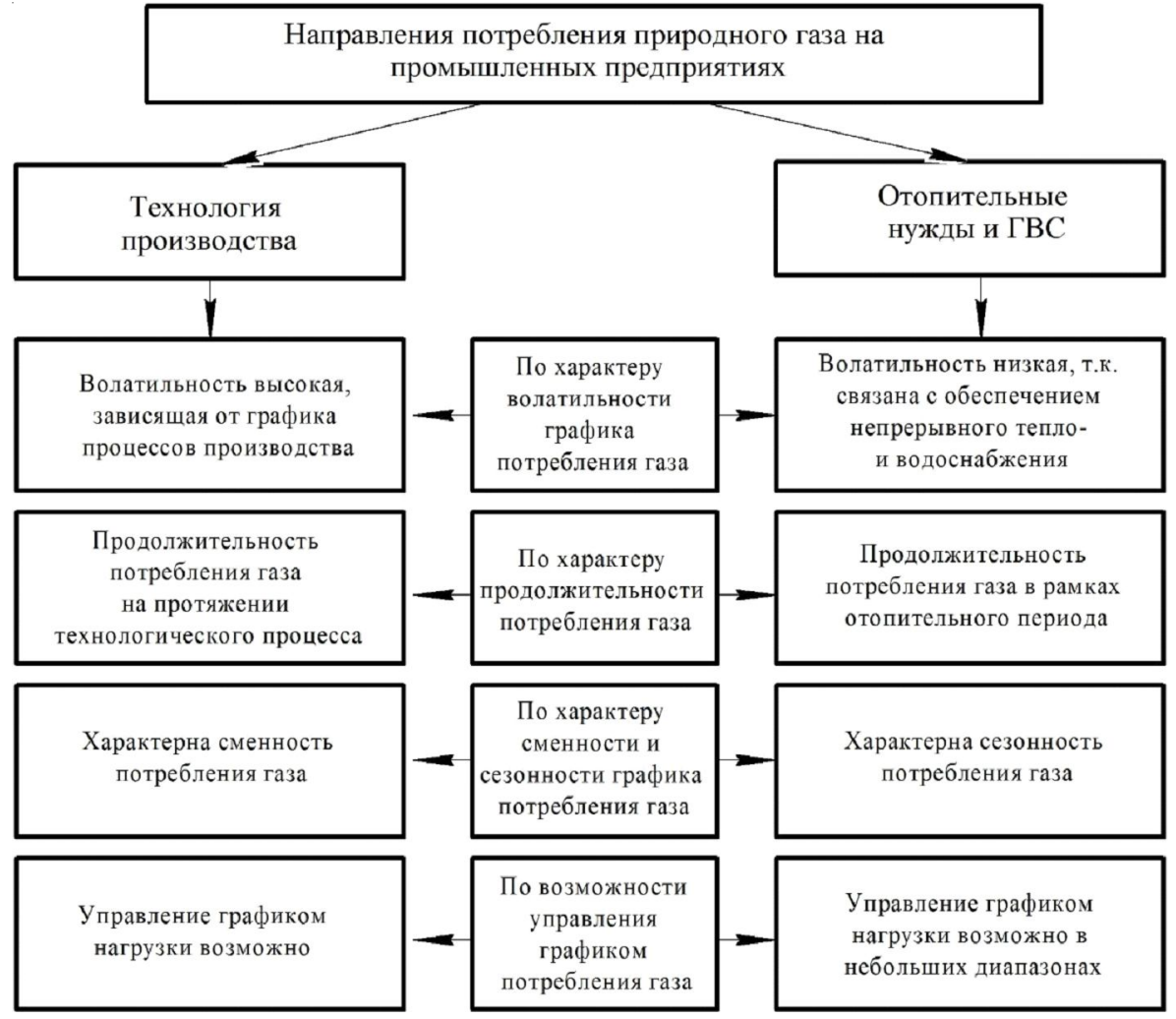

Рис. 5. Классификация направлений использования природного газа на промышленных предприятиях

Примечание. Составлено авторами. 
На потребление природного газа влияют четыре основные категории факторов: производственные, технологические, социально-экономические и климатические. Анализ факторов, влияющих на потребление природного газа, был проведен в разрезе основных направлений его использования на промышленных предприятиях, и на рисунке 6 приведена их авторская классификация.

Производственные факторы - факторы, действующие на характеристики графиков потребления газа со стороны состава и графиков загрузки производственного оборудования, графиков работы смежных производственных процессов, плана производства продукции, а также аварий и режимов выполнения ремонтов оборудования.
Технологические факторы - факторы, действующие на характеристики графиков потребления газа со стороны особенностей и режимов технологии производства продукции, физических характеристик обрабатываемого сырья.

Социально-экономические факторы - факторы, действующие на характеристики графиков потребления газа со стороны социальноэкономических процессов жизнедеятельности людей, режима выходных и праздничных дней, сменности работы производства, продолжительности рабочих смен и перерывов.

Климатические факторы - факторы, действующие на характеристики графиков потребления газа со стороны природы, к которым можно отнести температуру окружаю-

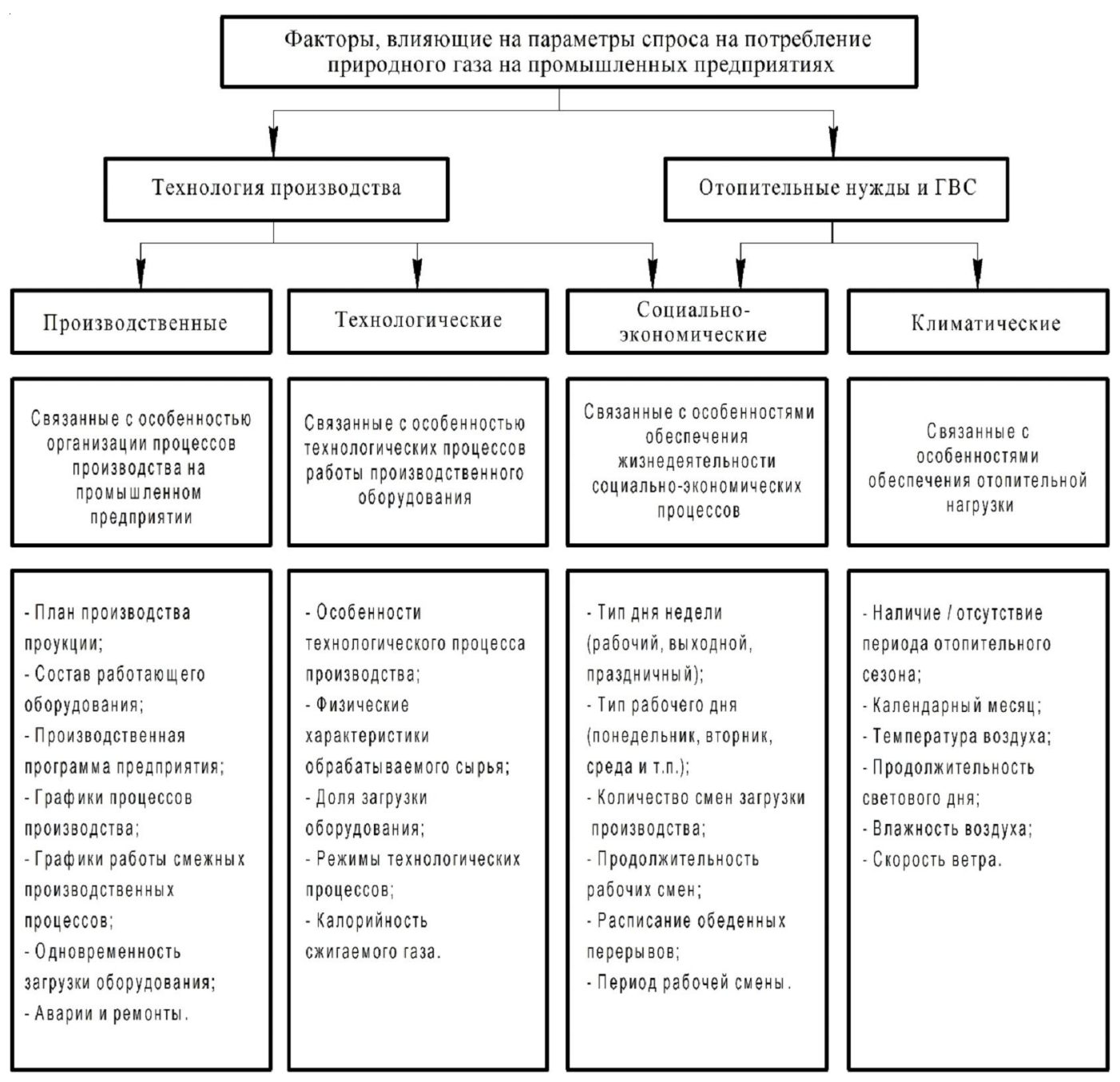

Рис. 6. Факторы, действующие на характеристики графиков потребления природного газа промышленными предприятиями

Примечание. Составлено авторами. 


\section{УПРАВЛЕНИЕ ЭКОНОМИЧЕСКИМ РАЗВИТИЕМ}

щего воздуха, продолжительность светового дня, влажность воздуха и осадки.

Как видно из классификации, при потреблении газа на технологические цели основное влияние на спрос оказывают факторы производственные, технологические и социальноэкономические. При потреблении газа на отопительные нужды и ГВС основными факторами выступают социально-экономические и климатические. Учет факторов, согласно разработанной классификации при прогнозировании краткосрочных параметров потребления газа на промышленном предприятии, позволит повысить точность выполняемых прогнозов и как следствие сократить затраты на оплату газоснабжения.

Уровень влияния каждой группы факторов на график потребления газа в существенной степени зависит не только от направления использования газа на промышленном предприятии, но и от отраслевой принадлежности предприятия, что отражено на рисунке 7.

Так, например, для предприятий металлургии наиболее высокое влияние на характеристики потребления газа оказывают производственные и технологические факторы, при среднем уровне влияния социально-экономических и низком уровне влияния клима- тических факторов. В таблице представлены сводные характеристики степени влияния выявленных четырех групп факторов на потребление газа в различных отраслях промышленности.

Учитывая значительное количество факторов, влияющих на параметры графиков спроса на потребление газа, их различную природу и уровень воздействия, для обеспечения точности выполнения прогнозов потребления газа мы предлагаем использовать комбинированную модель прогнозирования, сочетающую в себе использование статистических методов прогнозирования и метода экспертных оценок. Применение комбинированных методов прогнозирования в модели прогнозирования параметров краткосрочного спроса на потребление газа позволяет повысить точность выполняемых прогнозов, а также учесть в процессе выполнения прогноза более широкое число влияющих факторов. Описанию комбинированной модели прогнозирования потребления природного газа будет посвящена отдельная работа. Разработанная авторами концепция модели прогнозирования параметров краткосрочного потребления природного газа представлена на рисунке 8 .

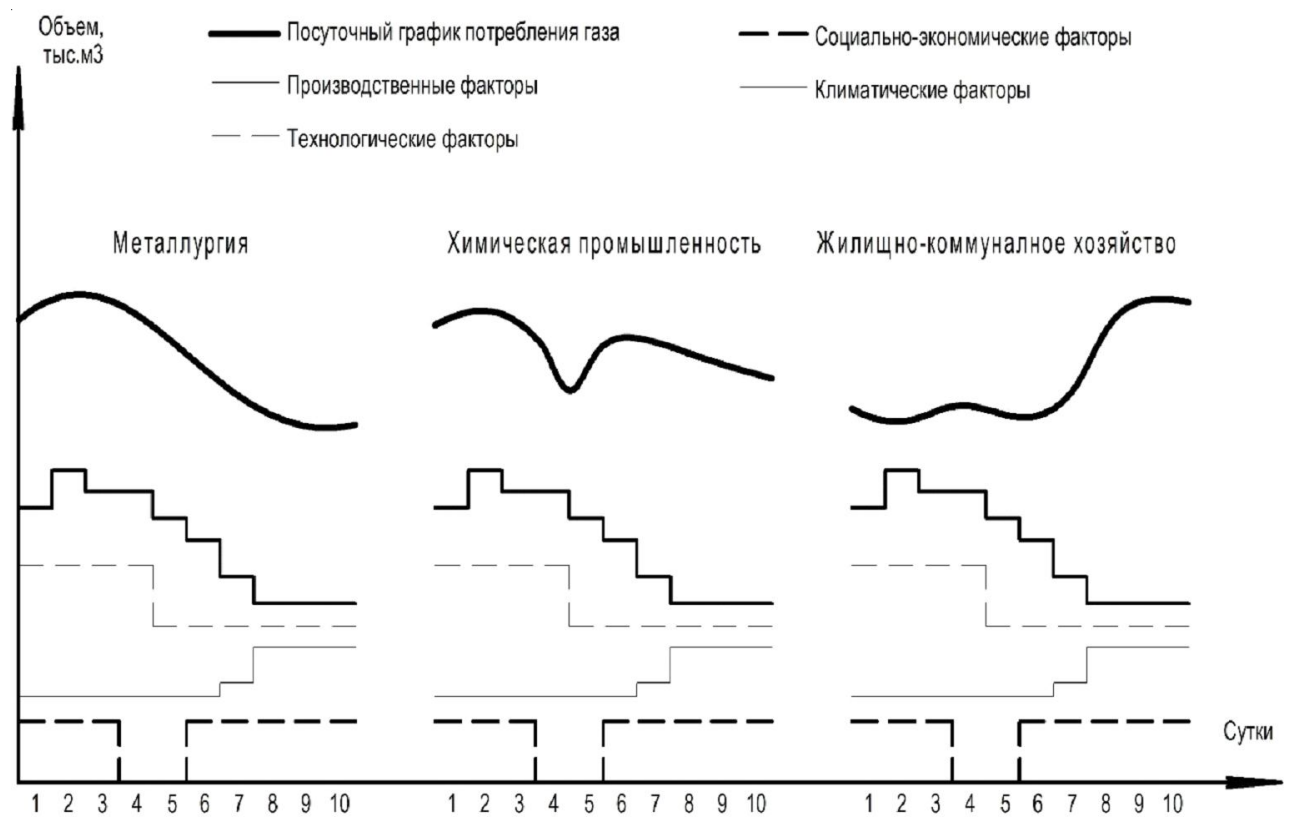

Рис. 7. Пример влияния различного типа факторов на параметры графика спроса на газ различными типами промышленных предприятий

Примечание. Составлено авторами на основе данных потребления газа АО «Пермский завод “Машиностроитель”», МЗ «Камасталь», ООО «Староцементный завод», ПАО «Уралкалий». 
А.П. Дзюба, И.А. Соловьева. Прогнозирование параметров потребления природного газа

Таблица

\section{Влияние выявленных типов факторов на потребление газа}

в различных отраслях промышленности

\begin{tabular}{|l|c|c|c|c|}
\hline \multicolumn{1}{|c|}{ Отрасли промышленности } & $\begin{array}{c}\text { Производ- } \\
\text { ственные }\end{array}$ & $\begin{array}{c}\text { Технологи- } \\
\text { ческие }\end{array}$ & $\begin{array}{c}\text { Социально- } \\
\text { экономические }\end{array}$ & $\begin{array}{c}\text { Клима- } \\
\text { тические }\end{array}$ \\
\hline Машиностроение & Среднее & Среднее & Среднее & Среднее \\
\hline Обрабатывающее производство & Среднее & Среднее & Среднее & Низкое \\
\hline Металлургия & Высокое & Высокое & Среднее & Низкое \\
\hline Электрометаллургия & Низкое & Низкое & Низкое & Низкое \\
\hline Горнодобыча & Низкое & Низкое & Низкое & Среднее \\
\hline Химическая промышленность & Высокое & Высокое & Высокое & Низкое \\
\hline Нефтяная промышленность & Среднее & Среднее & Высокое & Низкое \\
\hline Производство огнеупоров & Высокое & Высокое & Среднее & Низкое \\
\hline Производство железобетона & Высокое & Высокое & Среднее & Среднее \\
\hline Производство цемента & Высокое & Высокое & Среднее & Среднее \\
\hline Целлюлозно-бумажное производство & Высокое & Высокое & Среднее & Низкое \\
\hline Деревообрабатывающее производство & Высокое & Высокое & Высокое & Низкое \\
\hline Сельскохозяйственное производство & Среднее & Среднее & Высокое & Низкое \\
\hline Производство пищевых продуктов & Среднее & Среднее & Высокое & Низкое \\
\hline Жилищно-коммунальное хозяйство & Высокое & Высокое & Низкое & Высокое \\
\hline ТЭЦ & Высокое & Высокое & Высокое & Высокое \\
\hline ГРЭС & Высокое & Высокое & Высокое & Высокое \\
\hline Установки малой генерации & Высокое & Высокое & Высокое & Высокое \\
\hline
\end{tabular}

Примечание. Составлено авторами на основе статистического анализа параметров потребления газа $\mathrm{AO}$ «Пермский завод “Машиностроитель”», МЗ «Камасталь», ООО «Староцементный завод», ПАО «Уралкалий».

$\begin{array}{ccc}\text { Блок разделения } & \text { Блоквыявления } & \text { Блоквыполнения } \\ \text { нагрузки потребления } & \text { дейсиствующих } & \text { прогноза на основе } \\ \text { газа по видам } & \text { факторов } & \text { комбинированного } \\ & \text { по признакам } & \text { метода }\end{array}$

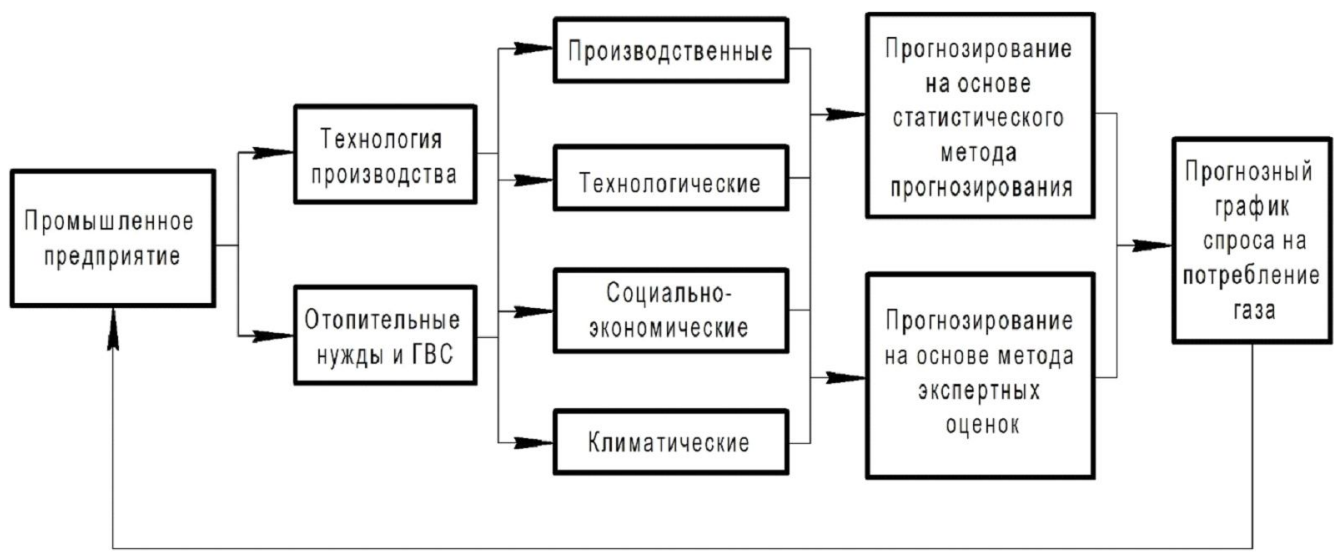

Рис. 8. Концепция модели прогнозирования краткосрочных параметров спроса на потребления газа промышленными предприятиями

Примечание. Составлено авторами.

Концепция модели прогнозирования краткосрочных параметров спроса на потребления газа промышленными предприятиями состоит из двух блоков: блока прогнозирования потребления газа на технологические цели и блока прогнозирования потребления газа на отопительные нужды и ГВС. Далее в рамках каждого блока прогнозируются будущие значения влияющих факторов, при этом их учет в модели прогнозирования производится соответствующим этой группе факторов методом. Результатом использования комбинированной модели прогнозирования является суммарный прогнозный график спроса на потреб- 
ление газа промышленного предприятия, который далее используется в рамках модели ценозависимого управления потреблением природного газа на промышленном предприятии, представленной на рисунке 1 .

Учитывая непрерывность процесса ценозависимого управления затратами на газ, прогнозирование параметров потребления природного газа целесообразно производить ежедневно, постоянно отслеживая обратную связь и совершенствуя модель прогнозирования. Контроль параметров потребления природного газа в модели ценозависимого управления производится в посуточном разрезе. Но для повышения точности выполняемых прогнозов посуточных параметров спроса на потребление природного газа мы предлагаем прогнозирование параметров спроса выполнять на каждый час, с последующим сложением полученных данных в посуточные результаты:

$$
Q_{\text {сутки }}^{\text {прогно }}=\sum_{n}^{\text {сутки }} Q_{\text {час }}^{\text {прогнз }},
$$

где $Q_{\text {сутки }}^{\text {проз }}, Q_{\text {час }}^{\text {прогно }}-$ прогнозные величины потребления природного газа на суточный и часовой периоды соответственно.

Таким образом, нами разработана концепция модели ценозависимого управления затратами на потребление природного газа, заключающаяся в корректировке собственного графика спроса промышленного предприятия на газ с учетом ценовых параметров единой системы газоснабжения. Базой ценозависимого управления затратами на газ является посуточный прогноз параметров его потребления. Разработанная концепция комбинированной модели прогнозирования параметров потребления природного газа позволяет существенно повысить точность прогнозов за счет разбивки графика потребления по видам использования газа, учета специфики и уровня влияния факторов в рамках каждого направления потребления и использования наиболее подходящих для каждой группы факторов методов прогнозирования.

Практическая значимость разработок заключается в возможности использования разработанной концепции модели прогнозирования параметров потребления природно- го газа любыми типами промышленных предприятий в рамках ценозависимого управления энергозатратами с целью их минимизации.

\section{СПИСОК ЛИТЕРАТУРЫ}

1. Агаев, Н. Б. Краткосрочное прогнозирование объема газопотребления с использованием искусственных нейронных сетей / Н. Б. Агаев // Нефтегазовое дело. - 2007. - № 1. - С. 23. - Электрон. текстовые дан. - Режим доступа: http://www.ogbus.ru. Загл. с экрана.

2. Башкин, В. Н. Изменение климата и прогноз потребления природного газа / В. Н. Башкин, Р. В. Галиулин // Газовая промышленность. - 2013. № 1 (685). - С. 58-61.

3. Гитман, И. С. Долгосрочное прогнозирование спроса на газ при наличии больших выборок потребителей / И. С. Гитман, К. А. Казак, Н. А. Кисленко // Системы управления и информационные технологии. - 2008. - № 1.3. - С. 349-352.

4. Емельяшина, Ю. В. Взаимовыгодные интересы производителей и потребителей газа в России / Ю. В. Емельяшина, С. В. Картошкин // Нефть, газ и бизнес. -2007 . - № 9. - С. 83-88.

5. Емельяшина, Ю. В. Национальные особенности спроса на газ / Ю. В. Емельяшина // Газовая промышленность. - 2007. - № 10. - С. 14-17.

6. Казак, К. А. Применение методов системного анализа для задач оценки прогнозов потребления газа / К. А. Казак // Наука и техника в газовой промышленности. - 2010. - № 2. - С. 19-22.

7. Колпакова, Н. В. Газоснабжение / Н. В. Колпакова, А. С. Колпаков. - Екатеринбург : Изд-во Урал. ун-та, 2014. - 200 с. - Электрон. текстовые дан. Режим доступа: http:/elar.urfu.ru/bitstream/10995/ 29016/1/978-5-7996-1185-9_2014.pdf(дата обращения: 21.07.2017). - Загл. с экрана.

8. Кузовкин, А. И. Модели прогнозирования спроса на природный газ / А. И. Кузовкин, В. М. Яценко // Микроэкономика. - 2010. - № 3. C. $9-12$.

9. Прогнозирование спроса на газ в субъектах РФ на основе формирования региональных ТЭБ / В. Э. Замерград, Л. А. Марфутов, Ю. А. Охорзин, Е. В. Сеннова // Газовая промышленность. 2009. - № 10. - C. 45-49.

10. Самсонов, Р. О. Формирование краткосрочных и долгосрочных прогнозов спроса на газ в России / Р. О. Самсонов, Н. А. Кисленко, К. А. Казак // Нефть, газ и бизнес. - 2007. - № 3. - С. 20-27.

11. Соловьева, И. А. Управление затратами на электропотребление по показателям волатильности спроса / И. А. Соловьева, А. П. Дзюба // Вестник 
Казанского государственного энергетического университета. - 2017. - № 1 (33). - С. 36-43.

12. Соловьева, И. А. Управление спросом на электропотребление на мезоуровне по показателям волатильности / И. А. Соловьева, А. П. Дзюба // Вестник Ивановского государственного энергетического университета. - 2017. - № 1. - С. 76-86.

13. Управление спросом на энергию. Уникальная инновация для российской электроэнергетики / Л. Д. Гительман, Б. Е. Ратников, М. В. Кожевников, Ю. П. Шевелев. - Екатеринбург, 2013. - 120 с.

14. Demand-side management in China. Benefits, barriers, and policy recommendations/Natural Resources DefenseCouncil/B. Finamore, H. Zhaoguang, L. Weizheng [et al.]. - [S. 1.], 2003. - 86 p. - Electronic text data. Mode of access: http://www.nrdc.org/air/energy/ chinadocs/dsm. pdf (date of access: 21.07.2017). - Title from screen.

15. Demand-side Management Strategies and the Residential Sector: Lessons from International Experience / A. B. Haney, T. Jamasb, L. M. Platchkov, M. G. Pollitt. Electronic text data. - Mode of access: www.eprg. group.cam.ac.uk (date of access: 21.07.2017). - Title from screen.

16. Understanding Cost-Effectiveness of Energy Efficiency Programs: Best Practices, Technical Methods, and Emerging Issues for Policy-Makers. Electronic text data. - Mode of access: http://www. epa.gov/cleanen ergy/documents/suca/costeffectiveness.pdf(date of access: 21.07.2017). - Title from screen.

\section{REFERENCES}

1. Agayev N.B. Kratkosrochnoye prognozirovaniye obyema gazopotrebleniya $\mathrm{s}$ ispolzovaniyem iskusstvennykh neyronnykh setey [Short-Term Forecasting of Gas Consumption Volume Using Artificial Neural Networks]. Neftegazovoye delo, 2007, no. 1, pp. 23. URL: http://www.ogbus.ru.

2. Bashkin V.N., Galiulin R.V. Izmeneniye klimata $i$ prognoz potrebleniya prirodnogo gaza [Climate Change and Forecast of Natural Gas Consumption]. Gazovaya promyshlennost, 2013, no. 1 (685), pp. 58-61.

3. Gitman I.S., Kazak K.A., Kislenko N.A. Dolgosrochnoye prognozirovaniye sprosa na gaz pri nalichii bolshikh vyborok potrebiteley [Long-Term Forecasting of Gas Demand in the Presence of Large Consumer Samples]. Sistemy upravleniya $i$ informatsionnyye tekhnologii, 2008, no. 1.3, pp. 349-352.

4. Emeliashina Yu.V., Kartoshkin S.V. Vzaimovygodnyye interesy proizvoditeley i potrebiteley gaza v Rossii [Mutually Beneficial Interests of Gas Producers and Consumers in Russia]. Neft, gaz i biznes, 2007, no. 9, pp. 83-88.
5. Emeliashina Yu.V. Natsionalnye osobennosti sprosa na gaz [National Features of the Demand for Gas]. Gazovaya promyshlennost, 2007, no. 10, pp. 14-17.

6. Kazak K.A. Primenenie metodov sistemnogo analiza dlya zadach otsenki prognozov potrebleniya gaza [Application of Methods of System Analysis for Estimating Gas Consumption Forecasts]. Nauka i tekhnika v gazovoy promyshlennosti, 2010, no. 2, pp. 19-22.

7. Kolpakova N.V., Kolpakov A.S. Gazosnabzhenie [Gas Supply]. Ekaterinburg, Izd-vo Ural. un-ta, 2014. 200 p. URL: http://elar.urfu.ru/ bitstream/10995/29016/1/978-5-7996-1185-9_2014.pdf (accessed July 21, 2017).

8. Kuzovkin A.I., Yatsenko V.M. Modeli prognozirovaniya sprosa na prirodnyy gaz [Models for Forecasting the Demand for Natural Gas]. Mikroekonomika, 2010, no. 3, pp.9-12.

9. Zamergrad V.E., Marfutov L.A., Okhorzin Yu.A., Sennova E.V. Prognozirovaniye sprosa na gaz $\mathrm{V}$ subyektakh RF na osnove formirovaniya regionalnykh TEB [Forecasting the Demand for Gas in the Constituent Entities of the Russian Federation on the Basis of the Formation of Regional TEBs]. Gazovaya promyshlennost, 2009, no. 10, pp. 45-49.

10. Samsonov R.O., Kislenko N.A., Kazak K.A. Formirovaniye kratkosrochnykh i dolgosrochnykh prognozov sprosa na gaz $\mathrm{v}$ Rossii [The Formation of Short-Term and Long-Term Forecasts of Gas Demand in Russia]. Neft, gaz i biznes, 2007, no. 3, pp. 20-27.

11. Solovyeva I.A., Dzyuba A.P. Upravleniye zatratami na elektropotrebleniye po pokazatelyam volatilnosti sprosa [Control of Electricity Consumption Costs by the Indicators of Demand Volatility]. Vestnik Kazanskogo gosudarstvennogo energeticheskogo universiteta, 2017, no. 1 (33), pp. 36-43.

12. Solovyeva I.A., Dzyuba A.P. Upravleniye sprosom na elektropotrebleniye na mezourovne po pokazatelyam volatilnosti [Demand-for-power Demand Control Based on Indices of Volatility]. Vestnik Ivanovskogo gosudarstvennogo energeticheskogo universiteta, 2017, no. 1, pp. 76-86.

13. Gitelman L.D., Ratnikov B.E., Kozhevnikov M.V., Shevelev Yu.P. Upravlenie sprosom na energiyu. Unikalnaya innovatsiya dlya rossiyskoy elektroenergetiki [Management of the Demand for Energy. A Unique Innovation for the Russian Electric Power Industry]. Ekaterinburg, 2013. 120 p.

14. Finamore B., Zhaoguang H., Weizheng L., et al. Demand-side management in China. Benefits, barriers, and policy recommendations. Natural Resources Defense Council, 2003. 86 p. URL: http:// www.nrdc.org/air/energy/chinadocs/dsm.pdf (accessed July 21, 2017).

15. Haney A.B., Jamasb T., Platchkov L.M., Pollitt M.G. Demand-side Management Strategies and the Residential Sector: Lessons from International 


\section{УПРАВЛЕНИЕ ЭКОНОМИЧЕСКИМ РАЗВИТИЕМ}

Experience. URL: www.eprg.group.cam.ac.uk (accessed July 21, 2017).

16. Understanding Cost-Effectiveness of Energy Efficiency Programs: Best Practices,
Technical Methods, and Emerging Issues for PolicyMakers. URL: http://www.epa.gov/cleanenergy/ documents/suca/cost-effectiveness.pdf (accessed July 21, 2017).

\section{Information about the Authors}

Anatoliy P. Dzyuba, Candidate of Sciences (Economics), Executive Director of Gazenergosbyt LLC, Salavata Yulaeva St., 15, office 53, 454021 Chelyabinsk, Russian Federation, gzyuba-a@yandex.ru.

Irina A. Solovyeva, Candidate of Sciences (Economics), Associate Professor, Department of Finance, Money Circulation and Credit, Higher School of Economics and Management, South Ural State University (National Research University), Prosp. Lenina, 76, office 310, 454080 Chelyabinsk, Russian Federation, solovevaia@susu.ru.

\section{Информация об авторах}

Анатолий Петрович Дзюба, кандидат экономических наук, исполнительный директор ООО «Газэнергосбыт», ул. Салавата Юлаева, 15, офис 53, 454021 г. Челябинск, Российская Федерация, dzyuba-a@yandex.ru.

Ирина Александровна Соловьева, кандидат экономических наук, доцент кафедры финансов, денежного обращения и кредита Высшей школы экономики и управления, Южно-Уральский государственный университет (национальный исследовательский университет), просп. Ленина, 76, ауд. 310, 454080 г. Челябинск, Российская Федерация, solovevaia@susu.ru. 